\title{
Effectiveness of hyaluronan on corneal epithelial barrier function in dry eye
}

Department of

Ophthalmology, Kyoto

Prefectural University

of Medicine, Kyoto,

Japan

N Yokoi

A Komuro

K Nishida

S Kinoshita

Correspondence to:

Norihiko Yokoi, MD,

Department of

Ophthalmology, Kyoto

Prefectural University of

Medicine, 465 Kajii-cho,

Hirokoji-agaru,

Kawaramachi-dori,

Kamigyo-ku, Kyoto 602,

Japan.

Accepted for publication 12 February 1997

Norihiko Yokoi, Aoi Komuro, Kohji Nishida, Shigeru Kinoshita

\begin{abstract}
Aims/background-The aim of this study was to assess quantitatively the effectiveness of hyaluronan on corneal disruption in patients with dry eye. Corneal epithelial barrier function was evaluated by measuring fluorescein permeability using a slit-lamp fluorophotometer.

Methods-11 patients with dry eye were assigned to this study. Hyaluronan ophthalmic solution ( $0.1 \%$ hyaluronic acid) was instilled five times a day to the right eye, in addition to the usual artificial tear solutions. The left eye received only the artificial tear solutions. Corneal barrier function was evaluated on the pretreatment day, and at 2 and 4 weeks after treatment. Fluorophotometry was used to measure fluorescein uptake at the central and lower corneal portions.

Results-Two weeks after treatment, hyaluronan treated right corneas showed significant corneal epithelial barrier improvement in the lower portion, compared with the pretreatment day $(p<0.025)$. Four weeks after treatment, the treated corneas showed significant improvement in the central corneal portion $(p<0.025)$ and improvement in the lower portion, compared with the pretreatment day. The untreated left corneas, on the other hand showed no improvement during the course of the study.

Conclusion-This study suggests that hyaluronan is effective in the treatment of corneal epithelial disruption in dry eye. (Br F Ophthalmol 1997;81:533-536)
\end{abstract}

The epithelium of the ocular surface functions as a barrier to the penetration of noxious substances into the cornea and maintains ocular surface integrity. ${ }^{1-3}$ Aqueous deficient dry eye is characterised by tear deficiency and an alteration of tear properties, which can cause epithelial barrier dysfunction, resulting in superficial punctate epithelial lesions, both of the cornea and conjunctiva. ${ }^{4}$ Many types of artificial tear have been developed to improve disturbed corneal epithelial surface and to relieve dry eye symptoms. ${ }^{56}$ Among these, hyaluronan (hyaluronic acid) has been reported to be effective in improving symptoms and lessening ocular surface epithelial damage ${ }^{7}$ and has been commercially available in Japan since 1995. This substance reportedly promotes corneal epithelial wound healing, ${ }^{8}$ protects the corneal epithelium, ${ }^{9}$ and possesses water retentive properties. ${ }^{10-13}$ In the treatment of dry eye, however, the efficacy of hyaluronan remains questionable, and both significant improvement ${ }^{14} 15$ and no significant improvement ${ }^{1617}$ have been reported in clinical trials.

Since the lower region of the corneal epithelium is preferentially damaged in cases of dry eye, the present study was directed towards the simultaneous evaluation of the barrier function of the central versus the lower portions of the cornea, using fluorophotometry. ${ }^{18-20}$ Using this method, the effectiveness of hyaluronan in ameliorating corneal epithelial disruption was assessed quantitatively in patients with dry eye.

\section{Patients and methods}

PATIENTS

Eleven patients with dry eye, aged $43-84$ years (mean 60.5 (SD 13.7) years), seven with Sjögren's syndrome and four without, were assigned to this study. Sjögren's syndrome was diagnosed on the basis of Fox's criteria. ${ }^{21}$ Dry eye had already been diagnosed on the basis of symptoms such as burning or a foreign body sensation, and on the basis of clinical tests including Schirmer's, with or without anaesthesia $(\leqslant 5 \mathrm{~mm})$, measurement of the tear break up time ( $\leqslant 5$ seconds), and evaluation of ocular surface staining with rose bengal $(\geqslant 3)^{22}$ and/or fluorescein $(\geqslant 1) .{ }^{23}$ Before this study, the patients had received artificial tears which were non-hyaluronan based, namely either preservative free solution containing $0.1 \% \mathrm{KCl}$ and $0.4 \% \mathrm{NaCl}$ (Softsantear, Santen Pharmaceutical Co Ltd, Osaka, Japan) or chondroitin sulphate solution containing 1\% chondroitin sulphate and chlorobutanol as a preservative (Chondron 1\%, Kaken Pharmaceutical Co Ltd, Tokyo, Japan).

Following informed consent, hyaluronan ophthalmic solution (HyaleinMini 0.1, Santen Pharmaceutical Co Ltd, Osaka, Japan) containing $0.1 \%$ hyaluronic acid (mean molecular weight: $60-120 \mathrm{Da}), \mathrm{NaCl}$ and $\mathrm{KCl}$, no preservatives, at a $\mathrm{pH}$ of 6.0-7.0, and an osmolarity ratio (relative to the osmolarity of $0.9 \%$ $\mathrm{NaCl}$ solution) of $0.9-1.1$, was applied to the right eye only every 2 hours during the daytime (five times a day), in addition to the artificial tear solution. The hyaluronan solution was instilled 1 minute after the application of the artificial tear solution. The left eye received only the artificial tear solution. No washout period was used in this study.

CHARACTERISTICS OF SLIT-LAMP FLUOROPHOTOMETER

In this study we used a slit-lamp fluorophotometer ${ }^{19}$ (modification of the ante- 
rior fluorometer, ${ }^{20}$ Kowa Co, Japan), with a wide measurement area $(0.3 \mathrm{~mm} \times 0.5 \mathrm{~mm}$; vertical $\times$ horizontal section). The longitudinal length of the focal diamond was $0.9 \mathrm{~mm}$ and $0.55 \mathrm{~mm}$ from the corneal surface along the horizontal and vertical sections, respectively. The maximal plane of the focal diamond of the receiving system could be easily adjusted to the corneal surface while the observer viewed the cornea from the front, and the fluorescent light could be received directly in front. This approach could be applied not only at the central cornea, but also at the peripheral cornea. A reticle with the three concentric circles also helped in the adjustment of the focal diamond maximal plane which had good reproducibility, especially in the peripheral cornea. A measurement angle (degrees of illumination system away from the receiving system in the horizontal plane) of $30^{\circ}$ was selected and measurement time was approximately $1.0 \mathrm{sec}-$ ond.

MEASUREMENT OF CORNEAL EPITHELIAL BARRIER FUNCTION

The fluorophotometric procedure used in this study to evaluate corneal epithelial barrier function was the same as that described in previous reports, ${ }^{19}{ }^{20}$ except that the barrier function of the lower portion of the cornea was also measured immediately after measurement at the central cornea. Briefly, after measurement of background fluorescence (autofluorescence) intensity at the central portion and at a point two thirds from the centre toward the lower limbus, $3 \mu \mathrm{l}$ of $0.5 \%$ (5 $\mathrm{mg} / \mathrm{ml}$ ) BSS Plus (Alcon) fluorescein solution was applied to each subject eye at the lower conjunctival sac with an Eppendorf micropipette, in non-contact fashion. Ten minutes after instillation, the eye was washed with 20 $\mathrm{ml}$ of BSS Plus. Thirty minutes after instillation (20 minutes after eye washing), fluorescence intensity was measured 10 times at the central and lower portions of the cornea. The background fluorescence value was then subtracted; the counts obtained were converted into fluorescein concentrations using low and high range calibration lines determined using the $0.50 \mathrm{~mm}$ wide slide glass corneal model ${ }^{19}$ (low range: $y=4.81+3.49 x \quad(0<x<22)$, high range: $y=-25.1+3.95 x \quad(23 \leqslant x \leqslant 1200) ; y=$ fluorescein concentration $(\mathrm{ng} / \mathrm{ml}), \mathrm{x}=$ measurement count). Within these ranges, linear correlations were obtained. From the concentration (corneal fluorescein uptake), corneal epithelial barrier function was evaluated.

PATIENT FOLLOW UP

The subjects were seen at 2 week intervals for 1 month, with the barrier function measured on the pretreatment day, 2 weeks after treatment, and 4 weeks after treatment.

STATISTICAL ANALYSIS

The fluorescein uptake data were analysed, throughout the testing, in terms of: (i) hyaluronan treated cornea (right eye) and untreated cornea (left eye); central and lower portions of

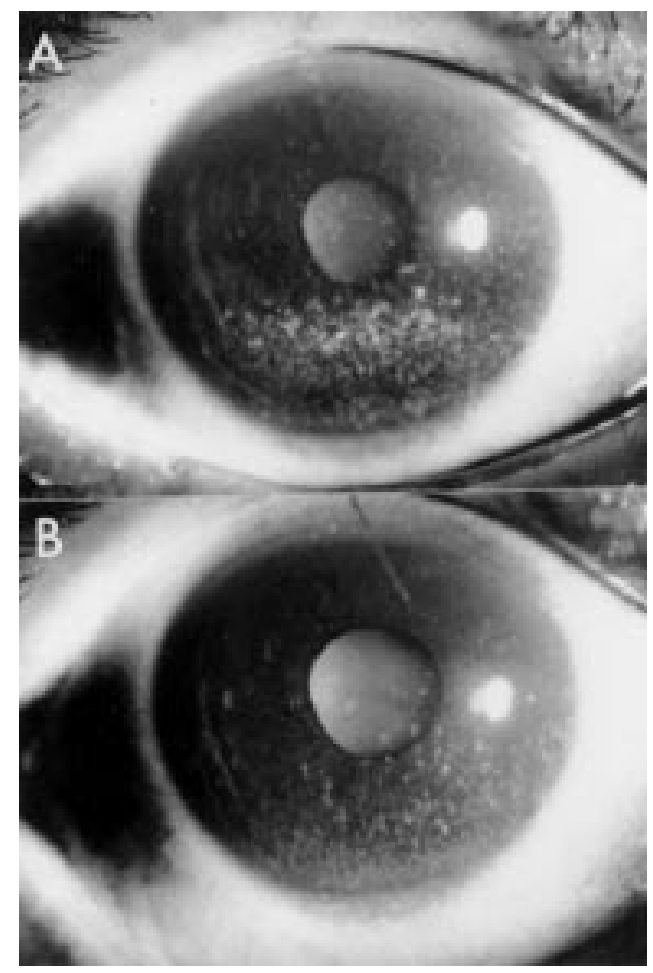

Figure 1 Representative superficial punctate keratopathy of corneal epithelium stained with fluorescein dye: before $(A)$ and 4 weeks after $(B)$ hyaluronan eyedrop treatment. Improvement is discernible.

the cornea; and (iii) the 3 days of corneal epithelial barrier measurements.

Data analysis was performed after all studies had finished by a ophthalmologist who did not participate in the corneal epithelial barrier function measurement. The values were analysed by the paired $t$ test and a $\mathrm{p}$ value of 0.05 or less was considered significant.

\section{Results}

CHANGES IN FLUORESCEIN UPTAKE AT THE LOWER PORTION OF THE CORNEA

On the pretreatment day, mean fluorescein uptake at the lower portion of the hyaluronan treated corneas (right eye) was 1314.6 (SE 379.5) $\mathrm{ng} / \mathrm{ml}(\mathrm{n}=10)$, while that in the untreated corneas (left eye) was 1352.0 (467.1) $\mathrm{ng} / \mathrm{ml}(\mathrm{n}=10)$.

Two weeks after treatment, these figures were $719.3(270.7) \mathrm{ng} / \mathrm{ml}(\mathrm{n}=10)$ and 1295.2 (494.7) $\mathrm{ng} / \mathrm{ml} \quad(\mathrm{n}=10)$ respectively, showing significant barrier function improvement in the treated corneas, compared with pretreatment values $(\mathrm{p}<0.025)$ (Figs 1 and 2$)$.

Four weeks after treatment, these respective figures were $625.0(216.4) \mathrm{ng} / \mathrm{ml}(\mathrm{n}=10)$ and 1227.6 (480.3) $\mathrm{ng} / \mathrm{ml} \quad(\mathrm{n}=10)$ respectively, showing no further barrier function improvement in the treated corneas and no significant improvement in the untreated corneas during the extended treatment course.

CHANGE IN FLUORESCEIN UPTAKE AT THE CENTRAL PORTION OF THE CORNEA (FIG 3) On the pretreatment day, fluorescein uptake at the central portion of the treated corneas (right eye) was $747.9(293.6) \mathrm{ng} / \mathrm{ml}(\mathrm{n}=11)$, while 


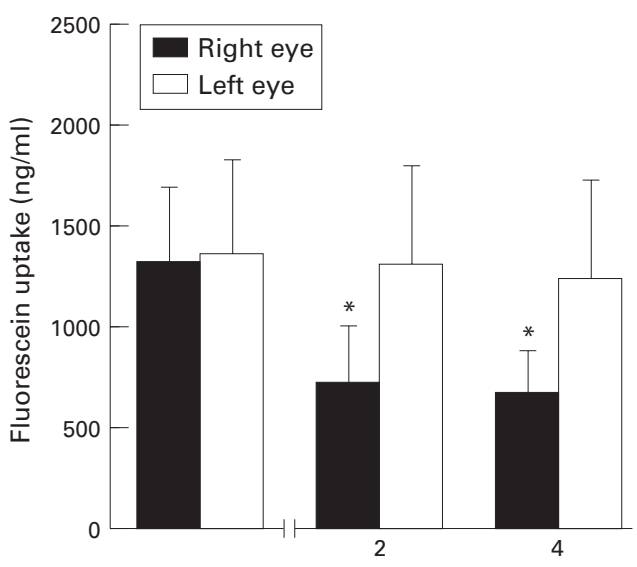

Pretreatment Weeks after treatment

Figure 2 Changes in fluorescein uptake at the lower corneal portion before and after treatment with hyaluronan eyedrops. Two weeks after treatment, the treated corneas (right eye) show significant barrier function improvement, when compared with pretreatment $(p<0.025)$. Four weeks after treatment, improvement in the lower part of the cornea is maintained. The untreated corneas (left eye) show no improvement in barrier function.

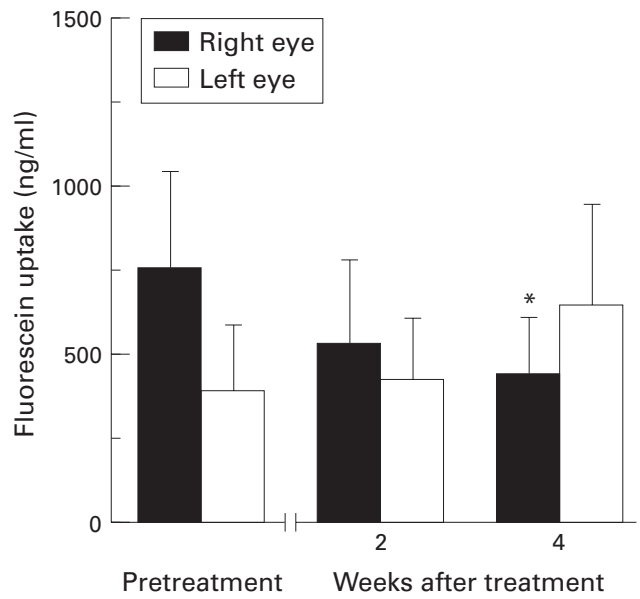

Figure 3 Changes in fluorescein uptake at the central corneal portion before and after treatment with hyaluronan eyedrops. Four weeks after treatment, the treated corneas (right eye) show significant barrier function improvement compared with pre-treatment $(p<0.025)$. The untreated corneas (left eye) show no improvement in barrier function.

that in the untreated corneas (left eye) was $388.0(194.4) \mathrm{ng} / \mathrm{ml}(\mathrm{n}=11)$.

Two weeks after treatment, the figures were $527.9(251.5) \mathrm{ng} / \mathrm{ml}(\mathrm{n}=11)$ and $417.4(180.9)$ $\mathrm{ng} / \mathrm{ml}(\mathrm{n}=11)$ respectively, showing no significant barrier function improvement in the treated corneas, compared with pretreatment values.

Four weeks after treatment, the figures were $436.3(169.3) \mathrm{ng} / \mathrm{ml}(\mathrm{n}=11)$ and 637.0 (302.0) $\mathrm{ng} / \mathrm{ml}(\mathrm{n}=11)$ respectively, with the treated eye showing a significant improvement $(\mathrm{p}<0.025)$.

\section{Discussion}

The present study showed the addition of hyaluronan treatment to be effective in improving corneal epithelial barrier function, both at the lower and central cornea, while conventional artificial tear application to the untreated eye afforded no barrier improvement. These results suggest that hyaluronan effectively improves the integrity of corneal superficial cells, as corneal epithelial barrier function is exerted mainly by the superficial layer of the epithelium.

Improvement in epithelial barrier function was seen at the lower portion earlier and was greater than at the central portion, but further improvement was not seen after 4 weeks of treatment. This earlier and greater improvement at the lower corneal portion suggests that hyaluronan may be better retained in the lower meniscus than in the central precorneal tears, which may be attributable to the differences in the distribution of hyaluronan within tears between the lower meniscus and the central precornea, resulting in greater or lesser water retention properties. ${ }^{1112}$

Barrier improvement appears to be unrelated to the simple increase in instillation resulting from the addition of hyaluronan. In our experience, increased instillation of the artificial tears used in this study does not cause the improvement seen in this study with hyaluronan. Summarising, in a previous study, we doubled the instillation times from 6 to 12 drops per day using the same non-hyaluronan based artificial tears as described previously, but only in the right eye of seven patients with dry eye. The left eye was left on the original six times instillation. Both eyes were subjected to identical fluorophotometric measurement, once on the pretreatment day and again 2 weeks later. The results showed that there was no significant improvement in the corneal epithelial barrier function of the right eye, either in the central or the lower portion. For example, the fluorescein uptake in the lower portion of the right eye on the pretreatment day was $120.5(46.9) \mathrm{ng} / \mathrm{ml}(\mathrm{n}=7)$, while 2 weeks after treatment, it was $75.2(21.5) \mathrm{ng} / \mathrm{ml}$ $(\mathrm{n}=7)$.

Various kinds of artificial tears have been developed to relieve symptoms and to improve the ocular surface epithelial damage associated with dry eye..$^{516}$ Among these products, hyaluronan, whose viscoelastic properties are known to help protect the corneal endothelium ${ }^{24}$ during intraocular surgical intervention, has also been shown to be of benefit as a tear substitute. ${ }^{7115}$ The water retentive properties of hyaluronan, as reflected by diminished fluorescein turnover within the tear meniscus, ${ }^{11}$ radioactive molecule turnover in precorneal tears, ${ }^{12}$ helps to preserve tear fluid and also provides tear film stability in dry eyes. ${ }^{10}$ Moreover, hyaluronan is known to actively promote corneal wound healing by accelerating cell migration. ${ }^{8}$ In the treatment of dry eye, these characteristics offer advantages over other artificial tears. The effectiveness of hyaluronan has been reflected in the alleviation of patient symptoms, ${ }^{71516}$ and in the diminishing of rose bengal staining score, ${ }^{15}$ mucus strand formation, and tear evaporation. ${ }^{25}$

Though the superficial layer of the corneal epithelium comprises a strong barrier, ${ }^{1-3}$ this layer is very susceptible to tear deficiency; even subclinical dry eye, which presents no clinical superficial punctate epithelial keratopathy, shows decreased barrier function 
fluorophotometrically. ${ }^{18}{ }^{20}$ In this study, therefore, given the experience of corneal epithelial barrier disruption in dry eye, ${ }^{18-20}$ we applied fluorophotometry as a sensitive and quantitative method of assessing improvement in barrier function after hyaluronan treatment. Fluorescein permeability was also measured, essentially simultaneously, at both the central and lower portions of the cornea, since the lower portion is often predominantly involved in dry eye.

Whether hyaluronan improves corneal epithelial barrier function through its ability to promote corneal epithelial cell migration, as well as by its water retentive properties, is not clear. This question will probably be resolved in future studies.

Supported in part by a research grant from Kyoto Foundation for the Promotion of Medical Science, and the intramural research fund of Kyoto Prefectural University of Medicine.

1 Klyce SD, Crosson CE. Transport processes across the rabbit epithelium: a review. Curr Eye Res 1985;4:427-32.

2 Wang Y, Chen M, Wolosin JM. ZO-1 in corneal epithelium: stratal distribution and synthesis induction by outer cell removal. Exp Eye Res 1993;57:283-92.

3 Wolosin JM, Chen M. Ontogeny of corneal epithelial tight junctions: stratal locale of biosynthetic activities. Invest Ophthalmol Vis Sci 1993;34:2655-64.

4 Lemp MA. Basic principles and classification of dry eye disorders. In: Lemp MA, Marquardt R, eds. The dry eye. Berlin: Springer-Verlag, 1992:101-31.

5 Lemp MA. Artificial tear solutions in the tear film and dry eye syndromes. Int Ophthalmol Clin 1973;13:221-9.

6 Lamberts DW, Langston DP, Chu W. A clinical study of slow-releasing artificial tears. Ophthalmology 1978;85:794800.

7 Polack MK, McNiece TM. The treatment of dry eyes with Na hyaluronate (Healon) A preliminary report. Cornea 1982;1:133-6.

8 Nishida T, Nakamura M, Mishima $H$, Otori T. Hyaluronan stimulates corneal epithelial migration. Exp Eye Res 1991;53:753-8.

9 Wysenbeek YS, Loya N, Ben Sira I, Ophir I, Ben Shaul Y. The effect of sodium hyaluronate on the corneal epithe- lium. An ultrastructural study. Invest Ophthalmol Vis Sci 1988;29:194-9.

10 Mengher LS, Pandlher KS, Bron AJ, Davey CC. Effect of sodium hyaluronate $(0.1 \%)$ on break-up time (NIBUT) in patients with dry eyes. Br F Ophthalmol 1986;70:442-7.

11 Shimizu A, Yokoi N, Nishida K, Kinoshita S. Hyaluronic acid and basal tear turnover. Invest Ophthalmol Vis Sci 1993;34(Suppl):1471

12 Gurny R, Ryser JE, Tabatabay C, Martenet M, Edman P, Camber O. Precorneal residence time in humans of sodium hyaluronate as measured by gamma scintigraphy. Graefes Arch Clin Exp Ophthalmol 1990;228:510-2.

13 Nakamura $M$, Hikida $M$, Nakano $T$, Ito $S$, Hamano $T$, Kinoshita S. Characterization of water retentive properties of hyaluronan. Cornea 1993;12:433-6.

14 Sand RB, Marner K, Norn MS: Sodium hyaluronate in the treatment of keratoconjunctivitis sicca. Acta Ophthalmol 1989;67:181-3.

15 Shinmmura S, Ono M, Shinozaki K, Toda I, Takamura E, Mashima Y, Tsubota K: Sodium hyaluronate eyedrops in the treatment of dry eyes. Br F Ophthalmol 1995;79:100711 .

16 Limberg MB, McCaa C, Kissling GE, Kaufman HE. Topical application of hyaluronic acid and chondroitin sulfate in the treatment of dry eyes. Am F Ophthalmol 1987;103:1947 .

17 Nelson JD, Farris RL. Sodium hyaluronate and polyvinyl alcohol artificial tear preparations. A comparison in patients with keratoconjunctivitis sicca. Arch Ophthalmol 1988;106:484-87.

18 Göbbels M, Spitznas M: Corneal epithelial permeability of dry eyes before and after treatment with artificial tears. Ophthalmology 1992;99:873-8.

19 Yokoi N, Kinoshita S, Akiyama K. A new slit-lamp fluorophotometer for the clinical evaluation of corneal epithelial barrier function. Nippon Ganka Gakkai Zasshi (Acta thelial barrier function. Nippon Ganka
Soc Ophthalmol fpn) 1994;98:641-7.

20 Yokoi N and Kinoshita S. Clinical evaluation of corneal epithelial barrier function with the slit-lamp fluorophotometer. Cornea 1995;14:485-9.

21 Fox RI, Robinson C, Curd J, Kozin F, Howell F. Sjögren syndrome: proposed criteria for classification. Arthritis Rheum 1986;29:577-84.

22 van Bijsterveld OP. Diagnostic tests in sicca syndrome. Arch Ophthalmol 1969;82:10-24.

23 Tsubota K, Toda I, Yagi Y, Ogawa Y, Ono M, Yoshino K. Three different type of dry eye syndrome. Cornea 1994;13: 202-9.

24 Graue EL, Polack FM, Balazs EA. The protective effect of Na-hyaluronate to corneal endothelium. Exp Eye Res 1980; 31:119-27.

25 Tsubota K, Yamada M. Tear evaporation from the ocular surface. Invest Ophthalmol Vis Sci 1992;33:2942-50. 